Original Research

\title{
Comparison of Attitudes Towards Meditation Healing Exercise between the Elderly Living with Chronic Illness in Bangkok and Surabaya
}

\author{
Ni Putu Wulan Purnama Sari ${ }^{1}$ and Jintana Artsanthia ${ }^{2}$ \\ 1 Faculty of Nursing, Widya Mandala Catholic University Surabaya, Indonesia \\ 2 Faculty of Nursing, Saint Louis College, Bangkok, Thailand
}

\begin{abstract}
Introduction: Meditation healing exercise (MHE) using the SKT technique is popular in Bangkok, Thailand, while in Surabaya, Indonesia, it is relatively new and unpopular. The attitude towards MHE depends on various internal and external factors. This study aimed to compare the attitude towards MHE between the elderly who are living with hypertension (HT) and/or diabetes mellitus (DM) in Bangkok and Surabaya.
\end{abstract}

Methods: This was a comparative study involving 96 and 100 elderly individuals with HT and/or DM in the communities of Surabaya and Bangkok respectively. The sample was chosen according to the aforementioned criteria. The sample size was 196. The instrument used was a valid and reliable questionnaire. Descriptive statistics, the Levene test, and an independent sample $\mathrm{T}$ test were used for the data analysis.

Results: The majority showed a positive attitude towards MHE; the higher Mean and lower SD was found in Bangkok (19.43 and 2.41). Out of the total, 87.5\% and $96.0 \%$ elderly had good attitude towards MHE in Surabaya and Bangkok respectively. There was a significant attitude difference in relation to the aspect of preferring to practice MHE between Bangkok and Surabaya $(\mathrm{p}=0.004)$. Overall, there was no significant attitude difference between Bangkok and Surabaya $(\mathrm{p}=0.17)$.

Conclusion: The elderly attitude towards MHE was mostly positive and good. The elderly in Bangkok prefer to practice MHE more than in Surabaya. There was no significant attitude difference in the elderly who are living with HT and/or DM between Bangkok and Surabaya. The implementation of MHE using the SKT technique has a high possibility of being accepted personally by the elderly in both sites.

\section{ARTICLE HISTORY}

Received: February 09, 2018

Accepted: June 29, 2018

\section{KEYWORDS}

attitude; elderly; meditation healing exercise

\section{CONTACT}

Ni Putu Wulan Purnama Sari \wulanpurnama@ukwms.ac.id $\Xi$ Faculty of Nursing, Widya Mandala Catholic University Surabaya, Indonesia

Cite this as: Comparison of Attitudes Towards Meditation Healing Exercise between the Elderly Living with Chronic Illness in Bangkok and Surabaya. Jurnal Ners, 13(1), 57-63. doi:http://dx.doi.org/10.20473/jn.v13i1.7607

\section{INTRODUCTION}

Non-communicable diseases (NCDs), or chronic diseases, are not passed from person to person. They are of a long duration and have a generally slow progression. The four main types of noncommunicable diseases are cardiovascular (e.g. hypertension), cancers, chronic respiratory diseases and diabetes mellitus (DM). 80\% of all NCD deaths occur in low- and middle-income countries. Almost three quarters of NCD deaths - 28 million - occur in low- and middle-income countries. 16 million NCD deaths occur before the age of $70 ; 82 \%$ of these "premature" deaths occurred in low- and middle- income countries. The greatest public health benefits are gained through the prevention of NCD (particularly cardiovascular diseases, cancers, and DM), injuries, and mental health disorders. These benefits can be achieved if the risk factors are identified and mitigated through appropriate interventions. If NCDs and mental illnesses are detected at an early stage and the appropriate controls initiated, then their severity can be significantly reduced (WHO, 2015).

Both Thailand and Indonesia are developing countries that face the threat of economic loss due to the burden of NCD. Efforts to optimise the clinical outcomes and quality of life are necessary to reduce 
the health expenditure associated with NCD. One way of doing this is by implementing nonpharmacological interventions, such as meditation practice on a daily basis. Meditation is an umbrella term that encompasses a family of practices that share some distinctive features, but vary in important ways in the context of their purpose and practice. Cardoso, et al. (2004) developed a detailed operational definition of meditation that was broad enough to include traditional belief-based practices and those that have been developed specifically for use in clinical settings. Using a systematic approach based on consensus techniques, they defined any practice as meditation if it (1) utilises a specific and clearly defined technique, (2) involves muscle relaxation somewhere during the process, (3) involves logic relaxation to analyse the possible psychophysical effects, not "to intend" to judge the possible results and not "to intend" to create any type of expectation regarding the process), (4) is a self-induced state, and (5) involves the use of a selffocus skill or "anchor" for attention.

Evidence of meditation healing exercise (MHE) effect on both physiological and neuropsychological aspects has been evaluated in 311 studies. The majority of studies have been conducted in healthy participants. Meta-analysis has revealed that the most consistent and strongest physiological effects from meditation practices in healthy populations occur in the reduction of heart rate, blood pressure, and cholesterol. The strongest neuropsychological effect was an increase in verbal creativity. There was also some evidence in before-and-after studies to support the hypothesis that certain meditation practices decrease visual reaction time, intraocular pressure, and increase breath holding time (Artsanthia \& Sari, 2017).

Thailand is famous for its meditation technique. Most of the citizens are Buddhist, and meditation is really close to Buddhist religious practice. One of the meditation experts from Bangkok, S. K. Triamchaisri, proposed eight new techniques for doing MHE named SKT 1-8. Each technique has its own health benefit. For instance, a study of Triamchaisri, et al. (2013) found that after practicing the SKT3 and SKT5 meditation exercises, the function of visual illusions was reduced, hearing problems and posture disorientation was $30 \%$ improved, and the quality of life of the patient related to eating, standing, sleeping was improved within one week. The improvement in relation to walking, posturing, hearing, sleeping, memory losing, and walking status was reported after regularly practicing three times a day for one month. $80 \%$ of the patient's spatial orientation was met after practicing for one month. There was a $90 \%$ level of holistic improvement in the visual and vestibular functions, which improved as per a healthy person within three months of practicing the meditation exercise.

Meditation practice in Indonesia, especially in Surabaya, is relatively new and unpopular in society, especially amongst the elderly who are living with
HT and/or DM in the communities. Most of the citizens in Surabaya are Moslem, and their daily religious practice does not involve any practice related to meditation. MHE is potentially being recognised as a new way of treating diseases. Meditation-related knowledge is potentially low, as well as the attitude towards MHE itself remaining unclear. Although most of Thailand citizens are familiar with meditation in practice, the elderly's attitude towards MHE, especially the SKT technique, remains unclear.

Attitude has always been a subject of interest to many researchers. It is considered exciting and mysterious. Attitude is the positive or negative evaluation or feeling that people have towards other people, objects, issues or events. Attitude includes the general way that people feel towards socially significant objects. Having a certain attitude in life could help people to live in harmony and be better understanding of the things around them. Attitude affects the way that people perceive and act towards other people, as well as the objects or events that they encounter (Abidin, et al, 2011).

This study aims to compare the attitude towards MHE between the elderly who are living with HT and/or DM in Bangkok (familiar with daily meditation practice) and Surabaya (relatively new to daily meditation practice). Our upcoming study aims to analyse the effect of MHE towards a handful of physical and psychological parameters in the elderly who are living with HT and/or DM in Bangkok and Surabaya. This prior study on attitude was important to conduct in order to ensure that there was a positive/good attitude towards MHE in both sites, so then the elderly would accept the study intervention personally and be determined to do meditation practice on a daily basis. This is important to assure that the MHE effects on the physical and psychological parameters are measured properly in the upcoming study. In our upcoming study, we will implement the SKT1 technique as proposed by S. T. Kantharadussadee, which could be useful for managing HT and/or DM with a good outcome, especially related to lowering blood pressure (BP) and blood sugar (BS) level.

\section{MATERIALS AND METHODS}

It was a comparative study involving 196 elderly individuals with DM and/or HT in communities around Bangkok and Surabaya. There were 100 and 96 cases compiled from Bangkok and Surabaya respectively. The sample distribution between the two study sites has been presented in Table 1.

Table 1. Sample distribution

\begin{tabular}{cccc}
\hline Case & Bangkok & Surabaya & Total \\
\hline DM & 30 & 30 & 60 \\
HT & 35 & 33 & 68 \\
DM\&HT & 35 & 33 & 68 \\
Total & 100 & 96 & 196 \\
\hline
\end{tabular}


The sample was chosen according to a set of criteria, who were then totally included in the study (total sampling). The inclusion criteria consisted of (1) elderly people who are willing to practice MHE using the SKT1 technique, and (2) they are consuming medication from a medical doctor to treat an appropriate disease. The exclusion criteria consisted of (1) elderly people who have heart and/or lung disease, and (2) they cannot communicate using Pasa Thai or Bahasa Indonesia.

The instrument used to measure attitude was developed by the researchers. It consisted of five items in the Likert scale format $(1=$ disagree until 5 = strongly agree). The attitude questionnaire was proven to be a valid and reliable instrument for measuring attitude towards MHE $(r=0.437-0.574$; IOC $=0.574 ;$ Cronbach's Alpha $=0.880$ ). A positive attitude is evident if the score $\geq 3$, while a negative attitude is evident if the score $\leq 2$ in each item. The total score was then categorised into four categories: $5-10=$ strongly negative, $11-15=$ negative, $16-20=$ positive, and 21-25 = strongly positive. These four categories were then merged at the end into two big categories of good and bad attitude. Good attitude was if the total score $\geq 16$, while bad attitude was if the total score $\leq 15$. Descriptive statistics, the Levene test, and an independent sample $\mathrm{T}$ test were used for the data analysis $(\alpha=0.05)$. Ethical clearance was issued by the Ethical Committee of Saint Louis College (SLC), Bangkok, Thailand (November, 2016); certificate number: E.038/2559. The attitude data was collected in the beginning of 2017 in the communities around Bangkok and Surabaya, while the pre-experimental study of the effect of MHE using the SKT1 technique on various physical and psychological parameters was conducted for the rest of the year. The principal investigator for our upcoming study is Jintana Artsanthia, from SLC, Bangkok. In Bangkok, there were five communities used as the study sites. In Surabaya, there were three communities used as study sites; RW V, VI, and VII in the district of Mojo.

\section{RESULTS}

In total, the study respondents were composed of $15.82 \%$ men and $84.18 \%$ women. The age range was $60-78$ years old. The educational background of the sample in Bangkok was mostly primary school level (53\%), while in Surabaya, it was mostly secondary school level $(64.58 \%)$. The income of the sample in Bangkok was $43 \%$ at THB $2000-6000$ per month, while in Surabaya, it was $53.13 \%$ at less than IDR 800 thousand per month. In Bangkok, most of the respondents had relatives who suffered from DM/HT (66\%), while in Surabaya, it was the opposite $(69.79 \%)$. Details of demography characteristic of study respondents are presented in Table 2 .

From Table 3, the average of the attitude score in Bangkok and Surabaya was 3.88 and 3.76 respectively, representing a positive attitude in both sites. The highest possible total score of attitude was
25. The results showed that the total score for attitude in Bangkok and Surabaya was 19.43 and 18.77, representing a good attitude in both sites. These results indicate that the study respondents could accept MHE on a personal level. There is a high possibility that the upcoming study respondents will do meditation practice regularly on a daily basis, allowing the MHE effects towards lowering BP and BS level to exist.

From Table 4, we can see that a $0 \%$ strongly negative attitude was found in Bangkok. This indicates that the communities in Bangkok were really familiar with meditation practice and the positive value of meditation already exists in the selected society. The most surprising fact was that a $19.79 \%$ strongly positive attitude was found in Surabaya. This result was even better than in Bangkok. This indicates that although the Surabaya communities are not really familiar with meditation practice and that the knowledge related to it is potentially low, the study respondents were optimistic towards meditation's benefit for their health.

From Table 5, we can see that even in Bangkok, most of the citizens are familiar with meditation practice. However, $4 \%$ of the study respondents had a bad attitude. It was not surprising that we found a higher result in Surabaya $(12.5 \%)$, because meditation practice is relatively new and unpopular in society. The relieving fact is that $62.24 \%$ respondents had a good attitude towards MHE in both sites. There was a high possibility that the upcoming study respondents will do meditation practice regularly on a daily basis, so that the MHE effect of lowering BP and BS level could exist.

From Table 6, we can see that the attitude in Bangkok was better than that in Surabaya because of the higher Mean and lower SD. This result indicates that the respondents in Bangkok had a good attitude towards MHE, in which the positive value was not really different between the focused societies.

All of the attitude data was normally distributed $(p>\alpha)$. There was significant attitude difference in the aspect of preferring to practice MHE (item 4) between Bangkok and Surabaya $(p=.004)$. This result indicates that the respondents from Bangkok like to practice meditation more than Surabaya's respondents. Based on the total score of attitude, overall, there was no significant attitude difference in the elderly who are living with HT and/or DM between Bangkok and Surabaya $(\mathrm{p}=.17)$

\section{DISCUSSION}

Attitudes have long been considered to be a central concept of social psychology. The concept of attitudes has changed over the years. The initial definitions were broad and encompassed cognitive, affective, motivational, and behavioral components. The current conception of attitude does not adequately distinguish between attitudes and factual beliefs on the one hand, or between attitudes and 
Table 2. Demographic characteristics

\begin{tabular}{|c|c|c|c|c|}
\hline \multirow[t]{2}{*}{ Characteristic } & \multicolumn{2}{|c|}{ Bangkok $(n=100)$} & \multicolumn{2}{|c|}{ Surabaya $(n=96)$} \\
\hline & $\sum$ & $\%$ & $\sum$ & $\%$ \\
\hline \multicolumn{5}{|l|}{ Sex } \\
\hline Male & 20 & 20.0 & 11 & 11.45 \\
\hline Female & 80 & 80.0 & 85 & 88.54 \\
\hline \multicolumn{5}{|l|}{ Age } \\
\hline $60-69$ & 48 & 48.0 & 75 & 78.13 \\
\hline 70 up & 52 & 52.0 & 21 & 21.87 \\
\hline \multicolumn{5}{|l|}{ Education } \\
\hline Primary school & 53 & 53.0 & 25 & 26.04 \\
\hline Secondary school & 25 & 25.0 & 62 & 64.58 \\
\hline Bachelor's degree & 8 & 8.0 & 9 & 9.38 \\
\hline No study & 14 & 14.0 & 0 & 0 \\
\hline \multicolumn{5}{|l|}{ Occupation } \\
\hline Agriculture or farmer & 1 & 1 & 0 & 0 \\
\hline $\begin{array}{l}\text { Shopkeeper or own } \\
\text { business }\end{array}$ & 10 & 10.0 & 12 & 12.50 \\
\hline Government officer & 2 & 2.0 & 1 & 1.04 \\
\hline $\begin{array}{l}\text { Other: housewife, retired, } \\
\text { etc }\end{array}$ & 87 & 87.0 & 83 & 86.46 \\
\hline \multicolumn{5}{|l|}{ Income per month } \\
\hline $\begin{array}{l}-<2,000 \text { baht } \\
\text { (<IDR } 800 \text { thousand) }\end{array}$ & 18 & 18.0 & 51 & 53.13 \\
\hline $\begin{array}{l}-6,000-2,000 \text { baht } \\
\text { (IDR } 800 \text { thousand }-2.4 \\
\text { million) }\end{array}$ & 43 & 43.0 & 31 & 32.29 \\
\hline $\begin{array}{l}-10,000-6,001 \text { baht } \\
\text { (IDR } 2.41-4 \text { million) }\end{array}$ & 19 & 19.0 & 10 & 10.42 \\
\hline $\begin{array}{l}->10,000 \text { baht } \\
\text { (> IDR 4 million) }\end{array}$ & 20 & 20.0 & 4 & 4.17 \\
\hline \multicolumn{5}{|l|}{ Relative has DM/HT } \\
\hline Yes & 66 & 66 & 29 & 30.21 \\
\hline No & 34 & 34 & 67 & 69.79 \\
\hline
\end{tabular}

Table 3. Frequency of the elderly attitude towards MHE

\begin{tabular}{|c|c|c|c|c|c|c|c|c|c|c|c|c|c|}
\hline \multirow[t]{2}{*}{ Item } & \multirow{2}{*}{ Attitude } & \multicolumn{6}{|c|}{ Bangkok $(n=100)$} & \multicolumn{6}{|c|}{ Surabaya $(n=96)$} \\
\hline & & 1 & 2 & 3 & 4 & 5 & Mean & 1 & 2 & 3 & 4 & 5 & Mean \\
\hline 1. & $\begin{array}{l}\text { Feel calm when } \\
\text { practicing MHE }\end{array}$ & - & 2 & 18 & 71 & 9 & 3.87 & 5 & 7 & 14 & 55 & 15 & 3.71 \\
\hline 2. & $\begin{array}{l}\text { Feel good when } \\
\text { practicing MHE }\end{array}$ & - & 4 & 23 & 63 & 10 & 3.79 & 4 & 2 & 21 & 56 & 13 & 3.76 \\
\hline 3. & $\begin{array}{l}\text { Believe that working on } \\
\text { the body and mind can } \\
\text { allow them to cooperate }\end{array}$ & - & - & 20 & 68 & 12 & 3.92 & 6 & 2 & 16 & 55 & 17 & 3.79 \\
\hline 4. & Prefer to practice MHE & - & - & 25 & 61 & 14 & 3.89 & 4 & 10 & 23 & 48 & 11 & 3.55 \\
\hline 5. & $\begin{array}{l}\text { Believe in the concept of } \\
\text { MHE, and that it can } \\
\text { improve immunity and } \\
\text { heal symptoms }\end{array}$ & - & 1 & 18 & 65 & 16 & 3.96 & 4 & 6 & 7 & 49 & 30 & 4.00 \\
\hline \multicolumn{3}{|c|}{ Average of attitude for each item } & & & & & $3.88(+)$ & & & & & & $3.76(+)$ \\
\hline \multicolumn{3}{|c|}{ Average of the total attitude score } & & & & & $\begin{array}{l}19.43 \\
\text { (Good) }\end{array}$ & & & & & & $\begin{array}{l}18.77 \\
\text { (Good) }\end{array}$ \\
\hline
\end{tabular}

preferences on the other. To hold an attitude is to ascribe an objective moral property to the attitude-object. However, the conception of such properties rests on an incoherent theory of relations as being constitutive of their terms, and the belief in them has only pseudo-cognitive content. Attitudes serve as rationalizations for concealed or unconscious impulses and are themselves defended by further rationalization. Some apparent exceptions, namely 'aesthetic attitudes' and 
Table 4. Level of the elderly attitude towards MHE based on the total score

\begin{tabular}{lccccc}
\hline \multicolumn{1}{c}{ Bangkok (n=100) } & \multicolumn{3}{c}{ Surabaya (n=96) } \\
\hline \multicolumn{1}{c}{ Total score } & $\Sigma$ & $\mathbf{0}$ & $\boldsymbol{\Sigma}$ & $\mathbf{\%}$ & Meaning \\
\hline $5-10$ & - & - & 5 & 5.21 & Strongly Negative \\
$11-15$ & 4 & 4 & 7 & 7.29 & Negative \\
$16-20$ & 82 & 82 & 65 & 67.71 & Positive \\
$21-25$ & 14 & 14 & 19 & 19.79 & Strongly Positive \\
Total & 100 & 100 & 96 & 100 & \\
\hline
\end{tabular}

Table 5. Category of the elderly attitude towards MHE based on the level of attitude

\begin{tabular}{lcccccc}
\hline \multicolumn{1}{c}{ Category } & Bangkok & \multicolumn{3}{c}{ Surabaya } & \multicolumn{1}{c}{ Total } & \% \\
\hline $\begin{array}{l}\text { Good attitude } \\
\text { (positive + strongly positive) }\end{array}$ & 96 & 96 & 84 & 87.5 & 122 & 62.24 \\
$\begin{array}{l}\text { Bad attitude } \\
\text { (negative + strongly negative) }\end{array}$ & 4 & 4 & 12 & 12.5 & 74 & 37.76 \\
\begin{tabular}{l} 
Total \\
\hline
\end{tabular} & 100 & 100 & 96 & 100 & 196 & 100 \\
\hline
\end{tabular}

Table 6. Descriptive statistics of the elderly attitude towards MHE

\begin{tabular}{lccc}
\hline \multicolumn{1}{c}{ Attitude in site } & $\sum$ & Mean & Std. Deviation \\
\hline Attitude in Bangkok & 100 & 19.43 & 2.41 \\
Attitude in Surabaya & 96 & 18.77 & 4.15 \\
Total - average & 196 & 19.10 & 3.55 \\
\hline
\end{tabular}

Table 7. Statistical test results on the elderly attitude differences towards MHE

\begin{tabular}{|c|c|c|c|c|c|c|c|c|c|c|}
\hline & \multirow{3}{*}{ Attitude } & \multicolumn{2}{|c|}{$\begin{array}{c}\text { Levene's Test } \\
\text { for Equality } \\
\text { of Variances }\end{array}$} & \multicolumn{7}{|c|}{ Independent t-test for Equality of Means } \\
\hline & & \multirow{2}{*}{$\mathbf{F}$} & \multirow{2}{*}{ Sig. } & \multirow{2}{*}{$\mathbf{t}$} & \multirow{2}{*}{ df } & \multirow{2}{*}{$\begin{array}{l}\text { Sig. (2- } \\
\text { tailed) }\end{array}$} & \multirow{2}{*}{$\begin{array}{c}\text { Mean } \\
\text { Difference }\end{array}$} & \multirow{2}{*}{$\begin{array}{l}\text { Std. Error } \\
\text { Difference }\end{array}$} & \multicolumn{2}{|c|}{$95 \% \mathrm{CI}$} \\
\hline & & & & & & & & & Lower & Upper \\
\hline \multirow[t]{2}{*}{ item1 } & $\begin{array}{l}\text { Equal variances } \\
\text { assumed }\end{array}$ & 19.440 & .000 & -1.398 & 194 & .164 & -.16167 & .11567 & -.38981 & .06647 \\
\hline & $\begin{array}{l}\text { Equal variances } \\
\text { not assumed }\end{array}$ & & & -1.384 & 151.724 & .169 & -.16167 & .11685 & -.39253 & .06919 \\
\hline \multirow[t]{2}{*}{ item2 } & $\begin{array}{l}\text { Equal variances } \\
\text { assumed }\end{array}$ & 2.294 & .132 & -.268 & 194 & .789 & -.02958 & .11053 & -.24757 & .18841 \\
\hline & $\begin{array}{l}\text { Equal variances } \\
\text { not assumed }\end{array}$ & & & -.266 & 178.868 & .790 & -.02958 & .11110 & -.24882 & .18965 \\
\hline \multirow[t]{2}{*}{ item3 } & $\begin{array}{l}\text { Equal variances } \\
\text { assumed }\end{array}$ & 14.773 & .000 & -1.226 & 194 & .222 & -.13875 & .11320 & -.36202 & .08452 \\
\hline & $\begin{array}{l}\text { Equal variances } \\
\text { not assumed }\end{array}$ & & & -1.213 & 150.653 & .227 & -.13875 & .11437 & -.36473 & .08723 \\
\hline \multirow[t]{2}{*}{ item4 } & $\begin{array}{l}\text { Equal variances } \\
\text { assumed }\end{array}$ & 23.456 & .000 & -2.917 & 194 & .004 & -.33792 & .11585 & -.56640 & -.10943 \\
\hline & $\begin{array}{l}\text { Equal variances } \\
\text { not assumed }\end{array}$ & & & -2.892 & 159.911 & .004 & -.33792 & .11686 & -.56871 & -.10712 \\
\hline \multirow[t]{2}{*}{ item5 } & $\begin{array}{l}\text { Equal variances } \\
\text { assumed }\end{array}$ & 7.823 & .006 & .248 & 194 & .804 & .02958 & .11912 & -.20535 & .26452 \\
\hline & $\begin{array}{l}\text { Equal variances } \\
\text { not assumed }\end{array}$ & & & .246 & 156.197 & .806 & .02958 & .12024 & -.20792 & .26708 \\
\hline \multirow[t]{2}{*}{ total } & $\begin{array}{l}\text { Equal variances } \\
\text { assumed }\end{array}$ & 9.165 & .003 & -1.365 & 194 & .174 & -.65917 & .48308 & -1.61193 & .29360 \\
\hline & $\begin{array}{l}\text { Equal variances } \\
\text { not assumed }\end{array}$ & & & -1.351 & 151.459 & .179 & -.65917 & .48800 & -1.62334 & .30500 \\
\hline
\end{tabular}

'authentic values', reveal themselves to be either (a) factual beliefs about aesthetic properties or about human motivation respectively, (b) preferences, or (c) moral attitudes as defined (Maze, 2008).
Conceptualisations of the attitude construct advances the possibility that attitudes can form in multiple ways. The three key means of attitude formation implicates cognitive, affective, or behavioral processes. An attitude is formed on the 
basis of cognitions when one comes to believe either that the attitude-object possesses (un)desired outcomes. The expectancy-value model argues that an attitude toward a given object is the sum of the expected value of the attributes of the object. An overall attitude toward the object is reached by taking the sum of the expected values of all of the attributes that an attitude object is thought to have. They claim that all attitudes are based on beliefs about the attitude object, and that all attitudes are formed via the summation of its subjective probabilities and values (Wigfield \& Cambria, 2010).

Most people seem to agree that an attitude involves at least three things: an attitude object which is defined by the attitude holder, a set of beliefs towards the object, and a tendency to behave in a certain way. Other underlying dimensions of attitude are knowledge level and strength or resistance to change. If the attitude intensity is high, then strength is also apt to be high. Strength may be high if one has lots of knowledge. There are also times when attitude seems to be change resistant despite a lack of knowledge. There is a reason to believe that an attitude that is high in intensity, strength, and knowledge is apt to be a good predictor of behavior; but attitude alone does not determine behavior (Hulleman, et al, 2010).

Based on Table 2, we can see that all of the respondents possessed a relatively low knowledge level based on their educational background (84.18\% in total). From Table 3, we can see that regarding the 5 items in the attitude questionnaire, most of the respondents tend to choose a higher score $(3 / 4 / 5)$ for each item. It is expected then that the respondents will practice MHE regularly, because 1) they intensely feel about MHE, 2) enough information was given prior to the study period, and 3) the high attitude intensity has made it change resistant.

Other than cognition, attitude forms from the effect that stems from an emotional reaction to the attitude object. One can be said to have an affectively-cased attitude when either positive or negative feelings are evoked when considering the attitude object. As seen in Table 3, 4 and 5, most of the respondents have a positive/good attitude toward MHE (91.84\% in total). Although most of the bad attitude was found to be in Surabaya (12.5\%), the overall attitude was mostly positive/good. There are three primary ways in which attitudes might be formed on the basis of affect: operant conditioning, classical conditioning, and mere exposure. Without clear feelings or beliefs about a potential attitude object, one may still have had past experiences with it. The past behavior can be used to infer the attitude toward an object through self-perception (Nagengast, et al, 2011).

One of the reasons that attitudes are practically and theoretically important is because they have predictable and very powerful effects on behavior (Nagengast, et al, 2011). People care passionately about some attitudes and consider them to be deeply important, and they accord no particular significance to other attitudes. Determining which attitudes most accurately predict which behavior under what circumstances has turned out to be a highly complex enterprise. Some research has revealed that some kinds of individuals are more likely than others to act on their held attitudes (Singh, et al, 2012). In addition, some kinds of situation are more likely than others to promote attitude-congruent behaviors (Tang, et al, 2014). In addition to differences across people and across situations, there are also marked differences across types of attitude - some kinds of attitude are more likely than others to motivate and guide behavior (Eaton \& Visser, 2008).

It is generally understood that a person's attitude has a primary influence on behavior. Banaji \& Eiphetz (2009) stated that if attitude is a predisposition to act favorably or unfavorably, then the attitude that one has should predict one's behavior. From the 1930s on, however, studies have shown the weak prediction of behavior from attitude (Abidin, et al, 2011); there are situational factors whose influence is stronger than mere attitude. People's expressed attitudes hardly predict their varying behavior (Wicker, 2010). Behavior and expressed attitude differs because both are subject to other influences. On any occasion, it's not only inner attitudes that guide us, but also the situation that we are face with.

The attitude model suggests that how you feel about some person, object, or idea will influence your behavior toward that object. However, it is not uncommon for people to have feelings one way and to behave differently. This difference may lead one to raise question about the relationship between attitude and behavior. It is apparent that there are intervening factors influencing the attitude behavior relationship: habit, social norms, and the expected consequences of behavior. Habits are automatic ways of behaving in appropriate situations with minimum thinking. Social norms include the role expectations of a certain behavior that members of a group, community, or society share. The expected consequences of a behavior produce an apparent inconsistency between what a person says and what a person does. Therefore, attitude is not always a good predictor of behavior (Tesser \& Schwarz, 2001).

The information that a person has about an object will influence the attitude that the person holds about that object. Many beliefs may underlie a given attitude. Individuals also use attitudes to express their basic values and to portray to others the sort of persons that they are. Generally, people maintain a consistent relationship between their beliefs, values, and attitudes. Attitudes are also influenced by personal needs, such as the need for reward, defending the ego, and understanding the environment. These three basic personal needs which attitudes serve are very important. Often, a set of beliefs and values are used to provide reasonable justification for an attitude. However, the real 
motivation for the attitude in question may be basic personal needs (Prasad, et al, 2011).

The attitude towards MHE in the elderly who are living with NCD, especially HT and/or DM, in Bangkok and Surabaya, was mostly positive/good and insignificantly different overall. Both Thailand and Indonesia are located in the South East Asia region, which is relatively similar regarding culture, habits, customs, and daily life. The beliefs, values, social norms, personal needs and expected consequences of behavior are also relatively similar in the study context. By way of this positive/good attitude regarding MHE expressed through the five items in the attitude questionnaire, the upcoming respondents are expected to practice MHE regularly on a daily basis so then its benefits for health can be assured.

\section{CONCLUSION}

The elderly attitude towards MHE was mostly positive/good in both sites. The elderly in Bangkok prefer to practice MHE more than in Surabaya. Overall, there was no significant attitude difference towards MHE between the elderly who are living with HT and/or DM in Bangkok or Surabaya. The implementation of MHE, especially using the SKT1 technique, in the elderly communities of Bangkok and Surabaya has the high possibility of being accepted on a personal level. Its effects on the various physical and psychological parameters involved in HT and DM management also possibly exist.

\section{REFERENCES}

Abidin, A.A.Z., Ibrahim, R., Akiah, S.A. (2011). Attitude (Part 1). Retrieved from: prints.utm.my/19940/1/001.pdf). (Accessed: November 19, 2017).

Artsanthia, J., Sari, N.P.W.P. (2017). The Effects of Meditation Healing Exercise in Elderly Who are Lliving with Non-communicable Disease in Bangkok and Surabaya. Bangkok: Faculty of Nursing, Saint Louis College.

Banaji, M.R., Eiphetz, L. (2009). Attitudes. Retrieved from:

www.fas.harvard.edu/ mrbworks/articles/2010 attitudes.pdf. (Accessed: November 19, 2017).

Cardoso, R., De Souza, E., Camano, L., et al. (2004). Meditation in health: an operational definition. Brain Res Protoc; 14(1): 58-60.

Eaton, A.A., Visser, P.S. (2008). Attitude importance: understanding the causes and consequences of passionately held views. Social and Personality Psychology Compass. pp. 1719-1736.

Hulleman, C. S., Schrager, S. M., Bodmann, S. M., Harackiewicz, J. M. (2010). A meta-analytic review of achievement goal measures: different labels for the same constructs or different constructs with similar labels?. Psychological bulletin, 136(3), 422.

Maze, J.R. (2008). The Concept of Attitude. Retrieved from:

http://aap.tandfonline.com/doi/abs/10.1080/00 201747308601684? journalCode $=\operatorname{sinq} 20$

(Accessed: November 19, 2017).

Nagengast, B., Marsh, H. W., Scalas, L. F., Xu, M. K., Hau, K. T., Trautwein, U. (2011). Who took the " $x "$ out of expectancy-value theory? A psychological mystery, a substantive-methodological synergy, and a cross-national generalization. Psychological Science, 22(8), 1058-1066.

Prasad, K., Wahner-Roedler, D.L., Cha, S.S., Sood, A. (2011). Effect of a single-session meditation training to reduce stress and improve quality of life among health care professionals: a "doseranging feasibility study. Alternative Therapies; 17(3). Retrieved from: www.proquest.com. (Accessed: November 19, 2017).

Singh, Y., Sharma, R., Talwar, A. (2012). Immediate and long-term effects of meditation on acute stress reactivity, cognitive functions, and intelligence. Alternative Therapies; 18(6). Retrieved from: www.proquest.com.

Triamchaisri, S.K., Triamchaisri, S., Sresumatchai, V. (2013). Effectiveness of SKT meditation innovation exercise on spatial disorientation: Thai traditional medicine. Alternative \& Integrative Medicine. DOI: 10.4172/23275162.S1.004.

Tang, Y.Y., Posner, M.I., Rothbart, M.K. (2014). Meditation improves self-regulation over the life span. Ann NY Acad Sci.Jan;1307:104-11. DOI: 10.1111/nyas.12227.

Tesser, A., Schwarz, N. (2001). Intrapersonal Processes (Blackwell Handbook of Social Psychology). Oxford, UK: Blackwell, pp. 436-457.

Wicker, A.W. (2010). Attitudes versus Actions: The Relationship of Verbal and Overt Behavioral Responses to Attitude Objects. Journal of Social Issues 25(4):41 - 78. •

Wigfield, A., Cambria, J. (2010). Expectancy-value theory: retrospective and prospective. Advances in motivation and achievement, 16, 35-70.

World Health Organization (WHO). (2015). Noncommunicable Diseases Progress Monitor 2015. ISBN: 9789241509459. 